\title{
Correlation between the ratio of T-bet/GATA-3 and the levels of IL-4 and IFN- $\gamma$ in patients with allergic asthma
}

\author{
YONG JI, GUO-QIANG CHEN, BIN HUANG and SONG WU \\ Department of Cardiothoracic Surgery, Jiangyin People's Hospital, Dongnan University, \\ Jiangyin, Jiangsu 214400, P.R. China
}

Received December 21, 2010; Accepted March 22, 2011

DOI: $10.3892 / \mathrm{mmr} .2011 .469$

\begin{abstract}
The aim of this study was to investigate the ratio of the transcription factors T-bet/GATA-3 in patients with allergic asthma. Forty-seven individuals with allergic asthma and 47 healthy control individuals provided $5 \mathrm{ml}$ of anticoagulated peripheral venous blood. Lymphocytes in peripheral blood were isolated by Ficoll and treated with phytohemagglutinin (PHA) at a final concentration of $100 \mathrm{mg} / 1$ for $48 \mathrm{~h}$. Interferon- $\gamma$ (IFN- $\gamma$ ) and interleukin-4 (IL-4) levels were detected using an enzyme-linked immunosorbent assay (ELISA), and the mRNA levels of both T-bet and GATA-3 were detected using reverse transcription polymerase chain reaction (RT-PCR). IFN- $\gamma$ levels in the lymphocytes of asthmatic patients were lower than those of the control group $(\mathrm{P}<0.05)$ and were positively correlated with the ratio of T-bet/ GATA-3. By contrast, IL-4 levels were significantly higher in asthmatic patients than in the control group $(\mathrm{P}<0.01)$ and were negatively correlated with the ratio of T-bet/GATA-3. In conclusion, the ratio of T-bet/GATA-3 can be used as an objective indicator of immune imbalance in patients with allergic asthma.
\end{abstract}

\section{Introduction}

Allergic asthma results from chronic airway inflammation involving a variety of cells, in particular mast cells, eosinophils, and $\mathrm{T}$ lymphocytes. Inflammation may cause recurrent episodes of wheezing, shortness of breath, chest tightness, and/or cough and other symptoms in susceptible individuals (1-3). The disease may significantly complicate life if treatment is not obtained or properly followed; therefore, allergic asthma has become a serious threat to public health as a major chronic disease. Recently, an imbalance between the expression of transcription factor T-box expressed in T cells (T-bet)

Correspondence to: Dr Yong Ji, Department of Cardiothoracic Surgery, Jiangyin People's Hospital, Dongnan University, 163 Shoushan, Jiangyin, Jiangsu 214400, P.R. China

E-mail: jiyongmyp@126.com

Key words: allergic asthma, transcription factors, immune regulation and GATA-binding protein-3 (GATA-3) was reported in bronchial asthma, particularly in allergic asthma $(4,5)$. Further research on the ratio of T-bet/GATA-3 would be helpful in understanding the etiology of asthma and developing immunotherapy methods. Here, we investigated the correlation between the ratio of the transcription factors T-bet and GATA-3 and the levels of interleukin-4 (IL-4) and interferon- $\gamma$ $(\mathrm{IFN}-\gamma)$ in 47 patients with allergic asthma.

\section{Materials and methods}

General information. Forty-seven patients were ascertained to have allergic asthma while visiting our hospital between February 2009 and 2010. Forty-seven healthy subjects visiting the hospital for physical examination were enrolled as the control group. The male to female ratio, age, height, weight and other characteristics were similar, with no significant differences $(\mathrm{P}>0.05)$ between the two groups. Patients were divided into four groups according to the grading criteria for patients with asthma aged 11 to 65 years: intermittent episodes (grade I) in 6 cases; mild persistent (grade II) in 19 cases; moderate persistent (grade III) in 17 cases; and severe persistent (grade IV) in 5 cases. The diagnostic criteria 'practical internal medicine' by Haozhu Chen were used for the diagnosis of asthma, which was subsequently confirmed by the novo-helisen-depot (NHD) skin-prick test for dust and the nasal provocation test. The healthy controls had no history of asthma, and all subjects with liver, kidney, cardiovascular disease, other serious life-threatening diseases or mental illness were excluded. The study was approved by the Ethics Committee of Jiangyin People's Hospital.

Methods. Patients consented to the collection of $5 \mathrm{ml}$ of early-morning fasting blood. Samples were anticoagulated with EDTA, and Ficoll (TBD, Tianjing) was added before centrifugation for $15 \mathrm{~min}$ at $1500 \mathrm{rpm}$. The mononuclear cell layer was collected and washed twice with phosphate-buffered saline (PBS). The cell concentration was adjusted to $2 \times 10^{6} \mathrm{ml}$ in $10 \%$ newborn-calf serum RPMI-1640 culture medium (Gibco). Phytohemagglutinin (PHA, Sigma) was added for a final concentration of $100 \mathrm{mg} / \mathrm{l}$, and cells were incubated for $48 \mathrm{~h}$ at $37^{\circ} \mathrm{C}$ in a $5 \%$ carbon dioxide atmosphere. Adherent cells were removed, and the lymphocyte suspension and supernatant were stored at $-20^{\circ} \mathrm{C}$. 
Table I. Primer sequences of T-bet, GATA-3 and $\beta$-actin.

Gene of interest

Primer

Sequence

Product length (human)

T-bet

Upstream primer $\mathrm{P}_{1}$

5'-CCTCGCACCTGGAGCTGGCTG-3'

GATA-3

Downstream primer $\mathrm{P}_{2}$

5'-CCTCGCACCTGGAGCTGGCTG-3'

Upstream primer $\mathrm{P}_{3}$

5'-CCTCGCACCTGGAGCTGGCTG-3'

Downstream primer $\mathrm{P}_{4}$

5'-CCTCGCACCTGGAGCTGGCTG-3'

$\beta$-actin

Upstream primer $\mathrm{P}_{5}$

5'-CCTCGCACCTGGAGCTGGCTG-3'

5'-CCTCGCACCTGGAGCTGGCTG-3'

Table II. Expression levels of IFN- $\gamma$ and IL-4 in plasma (mean $\pm \mathrm{SD})$.

\begin{tabular}{lccc}
\hline Group & No. & $\begin{array}{c}\text { IFN- } \gamma \\
(\mathrm{ng} / \mathrm{l})\end{array}$ & $\begin{array}{c}\text { IL-4 } \\
(\mathrm{ng} / \mathrm{l})\end{array}$ \\
\hline Asthma patients & 47 & $532 \pm 132$ & $107 \pm 27$ \\
Healthy controls & 47 & $868 \pm 108$ & $48 \pm 18$ \\
P-value & & $<0.01$ & $<0.01$ \\
\hline
\end{tabular}

Table III. Optical density (OD) value of T-bet and GATA -3 mRNA and T-bet/GATA ratio (mean $\pm \mathrm{SD})$.

\begin{tabular}{lrrrr}
\hline Group & No. & $\begin{array}{c}\text { T-bet } \\
\text { mRNA }\end{array}$ & $\begin{array}{c}\text { GATA-3 } \\
\text { mRNA }\end{array}$ & $\begin{array}{c}\text { T-bet/GATA } \\
\text { ratio }\end{array}$ \\
\hline Asthma patients & 47 & $0.12 \pm 0.08$ & $0.51 \pm 0.11$ & $0.24 \pm 0.73$ \\
Healthy controls & 47 & $0.17 \pm 0.07$ & $0.43 \pm 0.13$ & $0.40 \pm 0.54$ \\
P-value & & $<0.01$ & $<0.01$ & $<0.01$ \\
\hline
\end{tabular}

Determination of IL-4 and IFN- $\gamma$ levels. Expression levels of the cytokines IL- 4 and IFN- $\gamma$ were detected by an enzyme-linked immunosorbent assay (ELISA) in the culture supernatants. Kits were purchased from Shenzhen Jingmei Biotech Co., Ltd. and used according to manufacturer's instructions.

Determination of T-bet and GATA-3 mRNA expression levels. Extraction of total RNA from lymphocytes was performed with Trizol (Invitrogen) according to manufacturer's instructions. cDNA was synthesized using the SuperScript ${ }^{\mathrm{TM}}$ reverse transcriptase kit (Invitrogen). T-bet and GATA-3 cDNA was amplified by polymerase chain reaction (PCR) (Table I) with primers synthesized by Shanghai Biotechnology Co., Ltd. (Sangon). Cocktails containing 10X buffer $(5 \mu \mathrm{l}), 25 \mathrm{mmol} / \mathrm{l}$ magnesium chloride $(5 \mu \mathrm{l}), 10 \mathrm{mmol} / \mathrm{l} \mathrm{dNTP}(4 \mu \mathrm{l})$, cDNA template $(2 \mu 1)$, ExTaq polymerase $(0.3 \mu 1)$, and upstream and downstream primers (1 $\mu \mathrm{l}$ each) were combined for a total

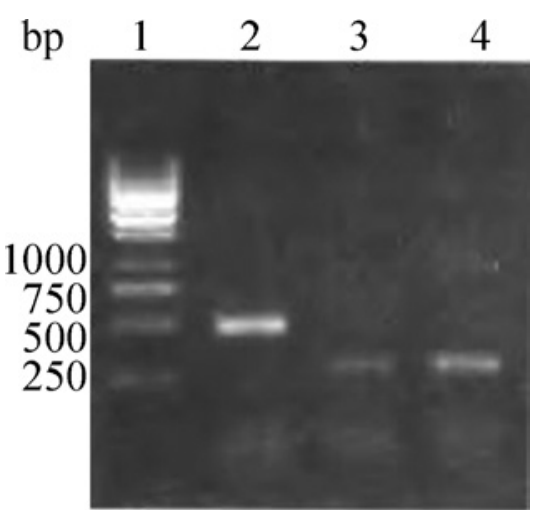

Figure 1. Polymerase chain reaction (PCR) amplification products of GATA-3, T-bet and $\beta$-actin in patients with allergic asthma. Lane 1, DNA marker; 2 , $\beta$-actin; 3 , T-bet; 4, GATA-3.

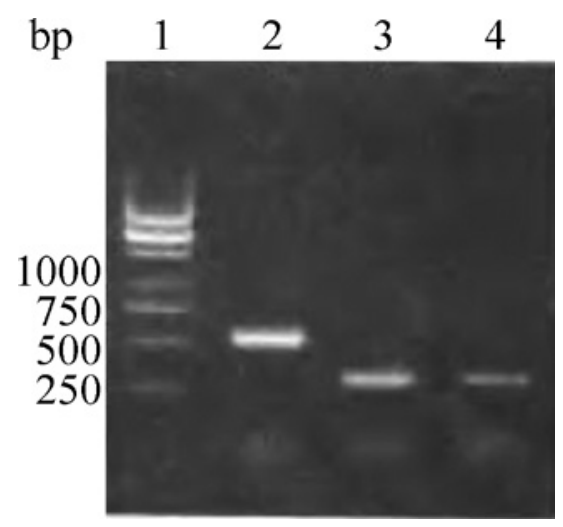

Figure 2. Polymerase chain reaction (PCR) amplification products of GATA-3, T-bet and $\beta$-actin in healthy controls. Lane 1, DNA marker; 2, $\beta$-actin; 3, T-bet; 4, GATA-3.

volume of $50 \mu \mathrm{l}$. Reaction conditions were as follows: $94^{\circ} \mathrm{C}$ for $5 \mathrm{~min} ; 94^{\circ} \mathrm{C}$ for $30 \mathrm{sec}, 60^{\circ} \mathrm{C}$ for $30 \mathrm{sec}$ and $72^{\circ} \mathrm{C}$ for $30 \mathrm{sec}$ (35 cycles); and $72^{\circ} \mathrm{C}$ for $10 \mathrm{~min}$. Ten $\mu 1$ of the PCR products of T-bet, GATA-3 and $\beta$-actin (internal control) were loaded onto a $1.2 \%$ agarose gel containing $0.5 \mathrm{mg} / \mathrm{l}$ of ethidium bromide. T-bet or GATA-3 bands were normalized against $\beta$-actin bands to determine the relative expression of the transcription factors. 

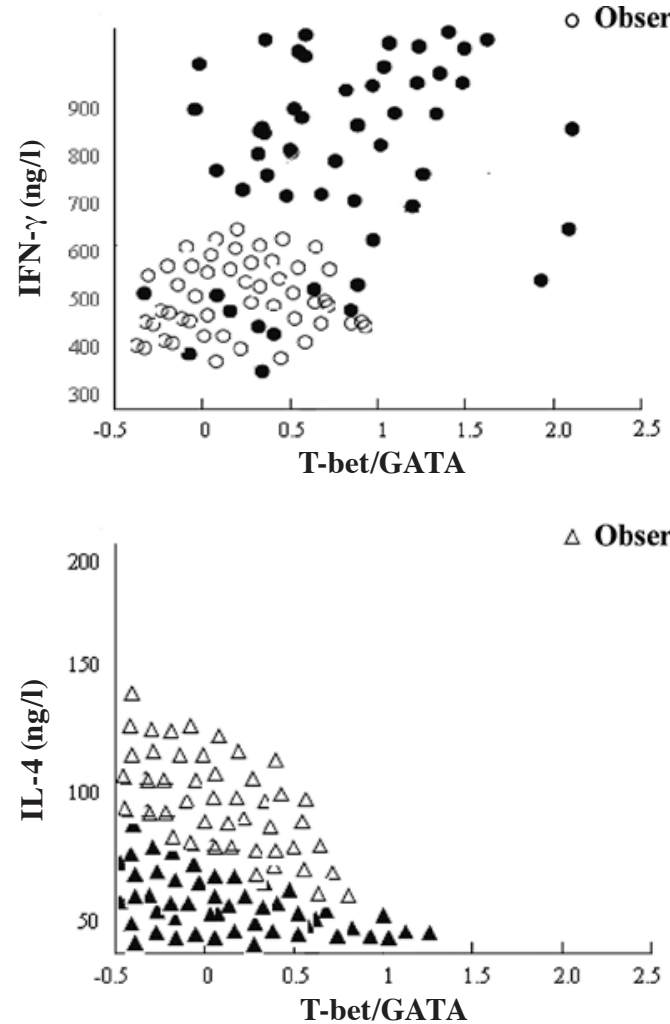

Figure 3. Correlation of T-bet/GATA ratio with IFN- $\gamma$ and IL-4.

Statistical analysis. SAS 10.0 statistical software was used for analysis of the study data. Using analysis of variance (Dunnett t-test), the measurement data were expressed as the mean \pm SD (using the $\chi^{2}$ test for the enumeration data, $\mathrm{P}<0.05$ was considered statistically significant).

\section{Results}

IL-4 and IFN- $\gamma$ levels in plasma. ELISA was used to detect the peripheral blood plasma levels of IFN- $\gamma$ and IL-4 in patients with allergic asthma. IFN- $\gamma$ was detected at lower levels in asthmatic patients than in normal controls, while IL-4 was detected at higher levels in these patients than in normal controls. Both of these differences were statistically significant $(\mathrm{P}<0.01)$, as shown in Table II.

Expression levels of T-bet and GATA-3 $\mathrm{mRNA}$ and the ratio of T-bet/GATA-3. RNA was extracted from lymphocytes and used in RT-PCR to determine the expression of T-bet and GATA-3. The expression of each of these transcription factors differed between asthma patients and control individuals, as shown in Figs. 1 and 2. Specifically, T-bet mRNA expression levels were lower in patients with allergic asthma than in the control group, while GATA-3 mRNA expression levels were higher in asthma patients than in the control. Thus, the T-bet/ GATA-3 ratio was significantly lower in the asthma group than in the control group $(\mathrm{P}<0.01$; Table III).

Correlation of T-bet/GATA-3 ratio with cytokines $I L-4$ and $I F N-\gamma$. The T-bet/GATA-3 ratio was positively correlated with IFN- $\gamma$ levels $(\mathrm{P}<0.05)$ and negatively correlated with IL-4 levels $(\mathrm{P}<0.05$; Fig. 3$)$.

\section{Discussion}

Allergic asthma commonly occurs in the general population, and frequently affects children. The disease is exacerbated by environmental factors such as viruses, allergens, and occupational exposure. While many questions still surround the etiology and evolution of allergic asthma, Th1 and Th2 cytokine patterns have now been implicated in several immune responses concerning infections, allergy, and autoimmunity $(6,7)$. The development of allergen-specific Th2 lymphocytes represents the triggering event for the recruitment and activation of IgE-producing B cells and fibroblasts. The subsequent release of soluble factors thus gives rise to the inflammatory reaction observed in this disease.

GATA-3 was identified as a cell lineage-specific factor selectively expressed and activated in the Th2 lineage. This transcription factor is the only one currently known to control the synthesis of all the key Th2-type cytokines, including IL-4, IL-5, and IL-13 $(8,9)$.

T-bet, identified in 2000 as a member of the T-box family, is a new Th1-restricted transcription factor. This transcription factor can be expressed in blood cells including bone marrow, umbilical cord blood progenitor cells and stem cells (10-13), mainly in $\mathrm{CD}^{+} \mathrm{T}$ cells. T-bet expression during $\mathrm{T}$ cell activation is strongly dependent on IFN- $\gamma$. Of note, cells secreting IL-4 are Th2-type cells, cells secreting IFN- $\gamma$ are Th1-type cells, and the IFN- $\gamma / \mathrm{IL}-4$ ratio indicates the ratio of Th1/Th2 cells. The expression of T-bet increases rapidly in the early stages of Th1 cell development, but is not expressed during Th2 cell development. Thus, GATA-3 and T-bet play a crucial role in the differentiation and regulation of Th cells.

Our study shows that IFN- $\gamma$ levels are positively correlated with the expression of T-bet mRNA, and IL-4 levels are positively correlated with the expression of GATA-3 mRNA. The secretion of IL-4 in the peripheral blood lymphocytes of patients with allergic asthma was markedly increased, and the production of IFN- $\gamma$ was decreased, confirming that Th2 cell subsets are dominant in patients with allergic asthma. Correspondingly, increases were observed in the expression of GATA-3 mRNA in the lymphocytes of these patients, and decreases were observed in the expression of T-bet mRNA. These results confirm the dominance of Th2 cells in patients with asthma. The results suggest that the transcription factor T-bet can directly induce Th1 cells to secrete IFN- $\gamma$, and GATA-3 can induce Th2 cells to produce IL-4. Thus, T-bet can promote Th1 development in patients with allergic asthma, while GATA-3 can promote Th2 development, and a reciprocal inhibitory effect exists between them.

A previous study reported changes in T-bet and GATA-3 expression in asthma patients, as well as changes in the numbers of Th1 and Th2 cells. Furthermore, using RT-PCR to directly determine the T-bet/GATA-3 ratio in mouse spleen lymphocytes may objectively and accurately show the balance state of Th1/Th2 cell subsets in mouse spleen lymphocytes (14-17). Similarly, our study demonstrated that the T-bet/ GATA-3 ratio in patients with allergic asthma was significantly lower than that in healthy controls, indicating that the ratio of T-bet/GATA-3 can be used as an objective indicator of immune imbalance in patients with allergic asthma. 


\section{References}

1. Zhang X and Köhl J: A complex role for complement in allergic asthma. Expert Rev Clin Immunol 6: 269-277, 2010.

2. Handoyo S and Rosenwasser LJ: Asthma phenotypes. Curr Allergy Asthma Rep 9: 439-445, 2009.

3. Hamid Q and Tulic M: Immunobiology of asthma. Annu Rev Physiol 71: 489-507, 2009.

4. Vale-Pereira S, Todo-Bom A, Geraldes L, Schmidt-Weber C, Akdis CA and Mota-Pinto A: FoxP3, GATA-3 and T-bet expression in elderly asthma. Clin Exp Allergy: Nov 28, 2010. doi: 10.1111/j.1365-2222.2010.03640 (E-pub ahead of print).

5. Kiwamot T, Ishii Y, Morishima Y, et al: Transcription factors T-bet and GATA-3 regulate development of airway remodeling. Am J Respir Crit Care Med 174: 142-151, 2006.

6. Zhang Q, Dong L and Li L: Investigation on using the T-bet/ GATA ratio as an indicator to evaluate the imbalance of Thl/Th2 in patients with asthma. J Cell Mol Immunol 1: 118-122, 2005.

7. Mosmanm TR and Sad S: The expanding universe of T-cell subsets: Th1, Th2 and more. Immunol Today 17: 138-146, 1996.

8. Ho IC, Tai TS and Pai SY: GATA3 and the T-cell lineage: essential functions before and after T-helper-2-cell differentiation. Nat Rev Immunol 9: 125-135, 2009.

9. Hwang SS, Lee S, Lee W and Lee GR: GATA-binding protein-3 regulates T helper type 2 cytokine and ifng loci through interaction with metastasis-associated protein. Immunology 131: 50-58, 2010.
10. Seki N, Miyazaki M, Suzuki W, et al: IL-4 induced GATA3 expression is a time-restricted instruction switch for Th2 cell differentiation. J Immuno 172: 6158 -6166, 2004

11. Pai SY, Kang BY, Sabadini AM, Parisini E, Truitt ML and Ho IC: Distinct structural requirements of GATA-3 for the regulation of thymocyte and Th2 cell differentiation. J Immunol 180: 1050-1059, 2008

12. Barnes PJ: Role of GATA-3 in allergic diseases. Curr Mol Med 8: 330-334, 2008.

13. Yu HR, Chang JC, ChenRF, Chuang H, Hong KC, Wang L and Yang KD: Different antigens trigger different Th1/Th2 reactions in neonatal mononuclear cells (MNCs) relating to T-bet/GATA-3 expression. J Leukoc Biol 74: 952-958, 2003.

14. Finotto S, Neurath MF, Glickman JN, et al: Development of spontaneous airway changes consistent with human asthma in mice lacking T-bet. Science 295: 336-338, 2002.

15. Höhler T, Reuss E, Adams P, et al: A genetic basis for IFN-gamma production and T-bet expression in humans. J Immunol 175: 5457-5462, 2005

16. Finotto $\mathrm{S}$ and Glimcher L: T cell directives for transcriptional regulation in asthma. Springer Semin Immunopathol 25: 281-294, 2004.

17. Chakir H, Wang H, Lefebvre DE, Webb J and Scott FW: T-bet/ GATA-3 ratio as a measure of the Th1/Th2 cytokine profile in mixed cell populations: predominant role of GATA-3. J Immunol Methods 278: 157-169, 2003. 